\title{
A prosopopeia da base nacional comum curricular e a participação docente
}

\author{
Nathália Fernandes Egito Rocha* \\ Maria Zuleide da Costa Pereira**
}

\begin{abstract}
Resumo
Este texto tem por objetivo refletir sobre o processo de elaboração do documento da Base Nacional Comum Curricular (BNCC), ressaltando a participação docente do contexto da prática da Rede Municipal de Ensino de João Pessoa - PB. Entendendo que o currículo situa-se num campo de disputas, assim sendo, ele nunca é apenas um conjunto neutro de conhecimentos. Ele expressa uma historicidade, um contexto, uma tensão. Portanto, considerando que a política precisa ser analisada em relação ao contexto, realizamos uma investigação a partir do Ciclo de Políticas de Stephen Ball e colaboradores (1992). No contexto das escolas, através dos discursos docentes, observamos os conflitos e contestação existentes que nos possibilitaram compreender a maneira como a política é percebida e interpretada por esses atores (as). Nossa intenção foi realizar uma análise baseada diretamente na experiência dos professores. Objetivamos perceber como o contexto da prática da Rede Municipal de Ensino de João Pessoa - PB atuou nesse processo de elaboração da política curricular.

Palavras-chave: Base Nacional Comum Curricular Participação; Micropolítica.
\end{abstract}

\section{The prosopope of the common curricular national base and teacher participation}

\begin{abstract}
This text aims to analyse the process of elaboration of the Base Nacional Comum Curricular (BNCC) document, highlighting the participation of the practice context of the João Pessoa - PB Municipal Teaching Network - PB. Understanding that the curriculum is located in a field of disputes, we realize that it is never just a neutral set of knowledge. It expresses a historicity, a context, a tension. In this way, we intend to identify these aspects in theprocess of the BNCC. Therefore, considering that the policy needs to be analyzed in relation to the context, we conducted an investigation from the Policy Cycle of Stephen Ball and collaborators (1992). In the context of schools, through the discourses of teachers, we observe the existing conflicts and contestations that enabled us to understand the way in which politics are perceived and interpreted by these actors. Our intention was to carry out an analysis based directly on the teachers' experience. We aim to understand how the context of the practice of the João Pessoa - PB Municipal Teaching Network worked in this process of curricular policy development.

Keywords: National Curricular Common Base; Participation; Micro-politic.
\end{abstract}

\section{Introdução}

Incorporadas a um complexo cenário político, econômico e social, as políticas curriculares brasileiras, no último biênio (2015/2017), caracterizaram-se pela centralidade das discussões em torno da política que propõe uma Base Nacional Comum Curricular (BNCC) para a Educação Básica.

A fim de acompanhar e caracterizar esse movimento em torno da política da BNCC, elaboramos um mapeamento que nos possibilitou refletir, analisar e formular algumas problematizações sobre a temática. Dentre os achados, percebemos que a participação representou a linguagem central da política curricular. Em relação aos processos de tessitura do documento, tanto em seu texto, quanto através da mídia, afirmase que a BNCC é "fruto de amplo processo de *Endereço eletrônico: nathaliafernandesufpb@ gmail.com ***Endereço eletrônico: mzul@uol.com.br debate e negociação com diferentes atores do campo educacional e com a sociedade brasileira em geral" (BRASIL, 2016, p. 24).

Portanto, propomo-nos, através de um trabalho de dissertação, analisar como se configuraram as discussões sobre a BNCC na escola, intencionado investigar as possibilidades e características do processo de participação da Rede Municipal de Educação de João Pessoa - PB na elaboração da política curricular em questão.

Posicionamo-nos, assim, por concordar com Cury (2014), quando indaga sobre a impossibilidade de uma proposta curricular ser legitimada sem a devida consideração da subjetividade dos profissionais da educação. $\mathrm{O}$ autor também afirma que o "desafio para qualquer democracia é a natureza e o grau de participação que deve pautar a relação dos dirigentes e dirigidos" (CURY, 2014, p. 54). Além de considerar a necessária "flexibilidade 
dos dispositivos normativos para que não impeça a crítica e a criatividade" (CURY, 2014, p. 54).

Nossa suposição foi de que a BNCC tipificou-se com o que Bourdieu (2004, p. 82) chama de prosopopeia, ou seja, uma "figura de retórica que consiste em falar no lugar de uma realidade ausente em nome de alguma coisa [...] Fala-se, portanto, em nome de um conjunto que se faz existir pelo fato de se falar em seu nome". Em outras palavras, consideramos que o caráter de participação na formulação da política de BNCC foi meramente formativo e que as condições para que essa participação fosse efetivada não foram garantidas, não sendo a formulação do documento, por isso, democraticamente participativa.

A feitura desse trabalho demandou-nos buscar um percurso metodológico que fosse capaz de analisar a política curricular em seus entremeios, que nos oferecesse a possibilidade de acompanhar o constante movimento da política, ressaltando seus efeitos e os rebatimentos em diferentes espaços e sujeitos. Neste sentido, percebemos que os trabalhos de Stephen Ball (1987) puderam nos subsidiar nesta tarefa.

Através do ciclo de políticas formulado pelo citado autor e pelos colaboradores (BOWE; BALL; GOLD, 1992) foi possível identificarmos alguns discursos que deram início à política com base em suas influências e analisarmos $\mathrm{o}$ processo de construção do documento da BNCC, percebendo a permanente existência de conflitos e acordos nessa tessitura, bem como investigarmos os efeitos e impactos produzidos pela política em outros espaços, especificamente os que foram gerados na micropolítica da escola. Nessas arenas, observamos que a política foi submetida a diferentes interpretações. Isto implica considerar que a política, a partir de uma perspectiva dinâmica, como o ciclo de políticas, não é inaugurada ou consumada através do texto legal.

Assim sendo, o presente texto configura-se como uma síntese de nossas análises no que se refere à problemática apresentada. Buscaremos revisitar e delinear as trilhas teórico-metodológicas que nos serviram de apoio para a realização do estudo. Nesse sentido, objetivamos tecer relações entre as categorias que se configuraram pilares em nossas análises: as políticas de currículo e a participação docente.

Portanto, organizamos este artigo em três sessões principais. Em um primeiro momento, discutiremos os rumos das políticas educacionais e curriculares da atualidade, partindo do pressuposto de que estas são mediadas pelas relações de poder, e com base nisto, analisaremos os direcionamentos políticos que sinalizaram para um currículo nacional. Posteriormente, explanaremos questões referentes à democracia e participação social. E, através da última sessão, apresentaremos nossos achados e análises sobre a experiência da Rede Municipal de Ensino de João Pessoa - PB na tessitura do documento.

Tentaremos, analiticamente, perceber as nuances desse encadeamento que se estabeleceu entre a BNCC e o contexto da prática das escolas. É nesse momento que apresentaremos os resultados do estudo, a partir das vozes dos sujeitos da escola. Finalmente, através das últimas considerações, apresentaremos nossas observações e reflexões sobre a problemática proposta. De antemão, ressaltamos que não buscaremos capturar a verdade sobre o tema, mas demonstrar, através de nossas problematizações, possibilidades e direções para pensarmos as políticas curriculares brasileiras atualmente.

\section{Normatividades curriculares: tensões entre o controle e a autonomia docente}

Ao analisar o contexto brasileiro atual, no qual as políticas curriculares são gestadas, Pereira (2010, p. 20) percebe o desenvolvimento de "um cenário permeado de dificuldades centradas na regulação curricular feita pelas instâncias mantenedoras, através do processo avaliativo classificatório a que são submetidos estudantes sem o devido preparo nas inúmeras escolas públicas no Brasil". Esses estudantes, por sua vez, são homogeneizados por meio da avaliação com base em um currículo que não contribui para o desenvolvimento das suas singularidades e que, pelo contrário, inibe-o.

Para a autora, nesse contexto, organiza-se um currículo que "impõe habilidades gerais a serem desenvolvidas por todos sem distinção de interação com o meio de origem" (PEREIRA, 2010, p. 27). Essa seleção curricular, na medida em que não se reflete sobre quem são os sujeitos "dessa aprendizagem, que experiências que eles trazem consigo, e o que já sabiam fazer, provoca uma série de insucessos na aprendizagem" (PEREIRA, 2010, p. 27).

No caso das políticas curriculares atuais, estabelece-se um cânone de conhecimentos considerados legítimos, cuja apropriação e qualificação devem ser auferidas pelas instâncias 
oficiais. Os estudos da citada autora, assemelham-se com as análises propostas por Apple (2000) ao considerar que, indiscutivelmente, o conhecimento é um instrumento de poder e, portanto, a sua seleção não se dá em termos neutros nem epistemológicos, nem políticos, nem ideologicamente e, por essa razão, constitui-se em uma arena de disputas.

Por outro lado, assumimos a compreensão de currículo em uma perspectiva autopoiética (PEREIRA, 2010, p. 25) e entendemos que ele se constitui de um "todo que se origina tanto das questões prescritas, como das questões curriculares da vida do aluno". Em outras palavras, a ideia de relacionar o processo de construção curricular com a categoria da autopoiése pressupõe "resistir aos currículos vistos, apenas como prescrição" [...], concebendo-o como "um processo vivo de inventividade dos sujeitos que fazem os espaços cotidianos da escola" (PEREIRA, 2010, p. 31).

Nesse entendimento, o currículo não se compõe apenas de "experiências trazidas de fora para dentro do espaço escolar". No processo autopoiético do conhecimento, "os sujeitos estabelecem interações de natureza histórica, social e biológica que se efetivam dentro e fora do espaço escolar com o objetivo de ensinar aprender" (PEREIRA, 2010, p. 34). Essa ideia assumida por Pereira (2010) nos remete a Santos (1995) quando defende que todo conhecimento é social e, nesse sentido, critica o modelo de racionalidade científica que rejeita o conhecimento do senso comum e na medida em que o assume como legítimo, revelando seu caráter totalitário.

Para Santos (2007), a partir dessa ideia, desenvolve-se uma "linha abissal" entre o que é legítimo e o que não é, ou seja, tudo o que não for cientificamente quantificável é ignorado. Esse pensamento é trazido por Süssekind (2014, p. 1517) com base nas ideias do referido autor, ao discutir sobre o currículo em uma perspectiva abissal, que "tece hierarquias de des-pertencimentos entre os conhecimentos que são reconhecidos como válidos, eficientes, adequados ou comuns nas construções curriculares, ou não".

Através de tal linha de pensamento, "esse currículo habita as construções curriculares no cotidiano das escolas criando exclusões, invisibilidades e inexistências, assim potencializa uma das mais importantes consequências das unificações curriculares para Pinar: a demonização dos professores". Diante dessa crítica, Santos (1995) propõe que seja valorizada "a inesgotável experiência que está em curso no mundo de hoje"
(SANTOS, 1995, p. 779), ou ainda, como afirma Süssekind (2014), que sejam considerados os currículos praticados e vivenciados na escola (OLIVEIRA, 2003).

Dito isso, e considerando as relações de poder tensionadas nos espaços escolares e nas tessituras das políticas curriculares, poderíamos nos questionar: quem realiza essa seleção ou distribui os lados da linha abissal do currículo? E de que modo esses atores são beneficiados ou prejudicados com essa triagem? De qual maneira as disputas (em todas as dimensões) são figuradas nessas arenas? Quais projetos e sentidos de currículo são cristalizados nas políticas curriculares atuais?

Para compreendermos essas questões, precisamos, considerar que, em cada fase histórica, corporificam-se novas significações de currículo recorrentes dos desdobramentos de como políticas públicas educacionais definem as concepções econômicas, políticas, sociais, culturais e educacionais.

Ball (2001, p. 100), analisando o período que corresponde da década de 1990 aos dias atuais, identifica a existência de um "conjunto de problemáticas conceptuais e um quadro de questões empíricas relacionadas com o surgimento de um novo paradigma de governo educacional". Esse projeto, para o autor, estabiliza-se tendo a globalização como base de sua sustentação. Fundamentado em estudos que identificam alguns efeitos desses fenômenos, os quais são chamados de transferência de políticas ou empréstimo de políticas, o referido pesquisador investiga o contínuo desaparecimento da:

[...] concepção de políticas específicas do Estado Nação nos campos econômico, social e educativo e, concomitantemente, o abarcamento de todos estes campos numa concepção única de políticas para a competitividade econômica, ou seja, o crescente abandono ou marginalização [não no que se refere à retórica] dos propósitos sociais da educação (BALL, 2001, p.100).

Ainda é observado por Ball (2001) que, a partir desse contexto da globalização, origina-se um conjunto de políticas tecnológicas ou um pacote de reformas que abarcam e relacionam as categorias de mercado, gestão e performatividade, o que resulta na transformação do próprio papel do Estado. Nessa lógica, o mercado é visto sob a ótica da neutralidade e como "um mecanismo para a oferta da educação mais eficaz, ágil e eficiente", transformando dessa maneira o seu próprio significado. Ou seja, "o 
mercado educacional tanto des-socializa, quanto resocializa; cria novas identidades e destrói a sociabilidade, encorajando o individualismo competitivo e o instrumentalismo. Os espaços nos quais são possíveis a reflexão e o diálogo sobre os valores são eliminados" (BALL, 2001, p. 107).

Os atores do processo educacional também se reconfiguram nessa lógica. $\mathrm{O}$ gestor assume um papel central nessa nova forma de gerenciamento, a qual deve infundir essas atitudes e culturas além de instrumentalizar a conduta dos demais sujeitos para o alcance das metas propostas. Por outro lado, tanto o ensino quanto a subjetividade dos docentes "alteram-se profundamente no contexto do novo panopticismo da gestão (da qualidade e excelência) e perante as novas formas de controle empresarial (através de marketing e competição)" (BALL, 2001, p. 109). Em contrapartida, configuram-se novas formas de monitoramento, ou também entendidas como regulação, que são os sistemas de avaliação, os quais se alinham os objetivos e estabelecem-se as comparações.

Destarte, desenha-se uma lógica em que "o desempenho [de sujeitos individuais ou organizações] funciona como medida de produtividade ou resultado, ou exposição de qualidade". E a performatividade é, portanto, executada quando esse processo "significa, resume ou representa a qualidade e o valor de um indivíduo ou organização num campo de avaliação". Dito isto, percebemos que a ideia de performatividade concorda com o que Süssekind (2014) discute sobre a demonização dos professores. Em termos gerais, Ball (2005) afirma que:

Os compromissos humanísticos do verdadeiro profissional - a ética do serviço - são substituídos pela teleológica promiscuidade do profissional técnico - o gerente. A eficácia prevalece sobre a ética; a ordem, sobre a ambivalência. Essa mudança na consciência e na identidade do professor apoia-se e se ramifica pela introdução, na preparação do professor, de formas novas de treinamento não intelectualizado, baseado na competência (BALL, 2005, p. 549).

Nesse sentido, a formação transforma-se em treinamento cujo objetivo primordial é, segundo o referido autor, a reformulação do professor enquanto um técnico e não um profissional crítico. Assim como Silva (2013) discorreu, a tarefa desse ator torna-se meramente burocrática. A prática da sala de aula, por sua vez, é "remodelada" a fim de "responder às novas demandas externas" (BALL, 2005, p. 550).

Os resultados desse pacote político e de tais exigências são "práticas inúteis ou até mesmo danosas que, no entanto, satisfazem os requisitos de desempenho", e, portanto, quantificados através de uma matriz de "avaliações, comparações e incentivos relacionados com o desempenho, os indivíduos e as organizações farão o que for necessário para se distinguir ou sobreviver" (BALL, 2005, p. 550). Através dos estudos do autor, percebemos que, imbuídas nessa política (neoliberal), as exigências tornam-se meramente funcionais ou instrumentais. O que nos reporta ao que Silva (2013, p. 25) discute. Para o autor, nessa perspectiva, o currículo torna-se uma questão de organização ou simplesmente uma mecânica e, com base em uma lógica industrial proposta por Tyler, a organização desse currículo corresponde "à divisão tradicional da atividade educacional: currículo; ensino e instrução e avaliação".

Através do incentivo da autorregulação (BALL, 2005) ou da "autodeterminação" (BOWE; BALL; GOLD, 1992, p. 66), espera-se que a escola (professores, em especial) assuma os riscos pelo fracasso ou pelo sucesso do projeto. Assim, corróise "qualquer sentido de um sistema educativo" e o substitui-se por um "conjunto diversificado orientado para o mercado de livre flutuação, de empresas [escolas], encarregadas pela entrega de produtos [pessoas educadas], com uma mínima especificação de qualidade [Currículo Nacional]" (p.66).

Esse discurso traz tanto como justificativa quanto como premissa a questão da qualidade. Passa-se a defender que a superação de problemas enfrentados nos países em acelerado processo de modernização, e inseridos no âmbito da globalização, será possível através da educação e de uma reforma curricular, fertilizando, assim, o terreno para a produção de políticas de currículo nacional.

Pereira e Santos (2006) analisam que essas políticas, no caso brasileiro, foram postas em prática pelo governo de Fernando Henrique Cardoso (19941998) com a promulgação da Lei 9394/96, que ratificou oficialmente as ações anteriormente postas pela Constituição Federal de 1988. Na análise das autoras, a Lei de Diretrizes e Bases da Educação (LDB) trouxe uma organização em todos os níveis de ensino. Inúmeros mecanismos foram criados para adequá-la às exigências da ordem econômica mundial. Os Parâmetros Curriculares, as Diretrizes e 
Parâmetros de ação - como mecanismo norteador e o Sistema de Avaliação da Educação Básica (SAEB), o Exame Nacional de Desempenho do Estudante de Nível Superior (ENADE), o Exame Nacional de Ensino Médio (ENEM) - como mecanismos reguladores - são heranças de um modelo neoliberal de educação.

Em consonância com as pesquisadoras, ainda que esses mecanismos possibilitassem uma possível organicidade às propostas curriculares materializadas nas diferentes realidades, eles desconsideram os avanços das concepções de currículo que privilegiam as construções coletivas e $\mathrm{o}$ respeito às singularidades locais e regionais. Para a autora, isso quer dizer "respeito às culturas dos sujeitos e, consequentemente, à identidade curricular de cada contexto" (PEREIRA; SANTOS, 2006 , p. 20). Nesse sentido, percebemos que a educação está estritamente relacionada à política da cultura.

Vale ressaltar que, na compreensão de Ball (1987, p. 227), não é razoável supor que esses resultados, no que diz respeito às mudanças no currículo, "são frutos de procedimentos racionais e burocráticos. Em grande medida, a mudança e a resistência a essa mudança dependem da influência relativa dos protagonistas sobre a tomada de decisões".

A pretensão de um Currículo Nacional é, mais uma vez, uma das discussões mais atuais no campo da educação brasileira, sobretudo em razão da elaboração de uma BNCC. Através do Ministério da Educação e aprovada pelo Conselho Nacional de Educação (Resolução $\mathrm{CNE} / \mathrm{CP} \mathrm{N}^{\circ}$ 2, de 22 de dezembro de 2017) a BNCC é apresentada como um:

[...] documento de caráter normativo que define o conjunto orgânico e progressivo de aprendizagens essenciais como direito das crianças, jovens e adultos no âmbito da Educação Básica escolar, e orientam sua implementação pelos sistemas de ensino das diferentes instâncias federativas, bem como pelas instituições ou redes escolares $(\mathrm{CNE} / \mathrm{CP}$ $\mathrm{N}^{\circ}$ 2, p. 4).

Portanto, considerando as ideias a esse respeito, identificamos o pano de fundo em que tal proposta se constitui e se inspira. Assim, quando Ball (1987, p. 260) analisa o processo de intervenção nos currículos, e neste caso na "implantação" de uma padronização curricular, ele afirma que esse conjunto de fatores pode reduzir-se a uma só questão: o controle.

Essas intervenções, segundo o autor, são exemplos do interesse do Estado em "mudar a ética do currículo escolar e de modificar o equilíbrio do controle sobre o processo de ensino". Essa tarefa para Ball (1987, p. 261) é executada através de mecanismos administrativos. Logo, exercendo o "controle do trabalho do professor mediante o uso de técnicas de administração", alcança-se a sujeição do ensino "a lógica de produção industrial e das competências do mercado".

Uma vez que se introduzem os docentes em sistemas de racionalidade administrativa, Ball (1987) afirma que eles são gradativamente excluídos de legítima participação efetiva no sentido de tomada de decisões substanciais. E, por outro lado, "o pragmatismo e as tecnologias de controle substituem as disputas ideológicas" (BALL, 1987). Como consequência, proletariza-se o trabalho do ensino e "em grande medida as escolas vão incorporando a ideologia da administração como único meio adequado de dirigir a organização" (BALL, 1987, p. 261).

Em linhas gerais, Bowe, Ball e Gold (1992, p.126) argumentam que uma proposta de Currículo Nacional atrelada a um sistema de avaliação tornase "fortemente prescritiva e repousa sobre um modelo fortemente normativo de aprendizagem", o que pressuporá "comparação entre sala de aula, institucional e de tamanho". Assim, por meio do Currículo Nacional, desenvolve-se "uma linguagem de hierarquia e comparação com base nos níveis de realização". E, "contra tudo isso, o professor deve proporcionar flexibilidade, ritmo diferencial, apoio individual em sala de aula, incentivo e reforço. Mas se surgirem problemas quem vai ser responsabilizado primeiro $-\mathrm{o}$ professor ou o Currículo Nacional?" (BOWE; BALL; GOLD, 1992, p. 126).

Os autores também salientam que em grande medida, o Currículo Nacional almeja a apropriação de habilidades, mas entendem que é dada pouca atenção "aos fatores práticos, financeiros, de mercado, e micropolíticos" que podem ser obstáculos para essa prática. A política da prescrição curricular limita tanto as questões de ensino, quanto as questões de tempo. Para Bowe, Ball e Gold (1992, p. 128), "isso afeta fundamentalmente a organização do processo de aprendizagem". O resultado disso é que, estando os professores enquadrados no currículo nacional e pressionados pelas avaliações externas, "podem encontrar-se respondendo às necessidades do 
currículo e da avaliação, ao invés das necessidades individuais dos estudantes" (p. 128).

Os autores não sugerem que todo o contexto que discutimos é um tipo de conspiração contra os professores, mas consideram que "os efeitos globais, da sucessão de iniciativas, das mudanças de controle e da tomada de decisões, assim como as alterações nas condições de trabalho, estão exercendo impacto na vida cotidiana dos professores" (BOWE; BALL; GOLD, 1992, p. 262). Ball (1987) entende que a pressão pelo controle do trabalho desses docentes e o aumento da intervenção direta em assuntos relativos ao currículo, constituem-se como intervenções sobre as escolas, de modo geral e os professores, individualmente, para que se adotem as normatividades curriculares (BALL, 1987).

Por outro lado, essas mesmas pressões e intervenções limitam que estes profissionais exerçam as primeiras influências no processo pedagógico (BALL, 1987). Em outras palavras, culmina-se um processo de demonização (SÜSSEKIND, 2014) do trabalho docente.

Moreira (2013) afirma que esses fatores mencionados não contribuem para fomentar práticas pedagógicas centradas na autonomia do professor. $\mathrm{Na}$ visão desse autor, faz-se necessário "examinar a possibilidade de construção de outra cultura [...] a questão do profissionalismo docente vem à tona para que se analise se e como é possível revigorá-lo, de modo que mais facilmente se encaminhe na contramão da cultura performatividade." (MOREIRA, 2013, p. 85).

No entendimento de Ball (1987, p.129), a autonomia docente pode ser conceituada como "um conjunto de liberdades para atuar, marcadas por limites estreitos e que podem ser retiradas ou reduzidas se se infringir esses limites". Por efeito, essa autonomia para o autor é "uma confortável ilusão que alimenta uma sensação de independência profissional nos professores, mas, no entanto, ata-se ao regime institucional de sua escola". Em outras palavras, a autonomia "é um importante compromisso entre liberdade e controle", isto é, a autonomia "tem uma poderosa arma função ideológica, mas tem implicações para estrutura do controle" (BALL, 1987, p. 129). O autor também conjectura que essa autonomia pode limitar-se a uma quantidade de assuntos, sobre os quais o professor pode exercer influência.

É nesse ponto que, a partir de Ball (1987), trazemos uma questão central nessa discussão: em que grau a dinâmica interna da micropolítica depende ou está condicionada por forças externas? Como resposta, o autor apresenta uma nova categoria para analisar esse contexto, a autonomia relativa. Para essa discussão, ele parte de duas premissas: uma é que a escola, como organização, não pode ser independente do seu entorno; a outra é a rejeição da ideia de adaptação, pressupondo que as forças externas exerçam um controle absoluto na micropolítica.

De acordo Ball (198, p. 95), “a micropolítica é um processo dinâmico que depende de habilidades, de recursos e de alianças entre os participantes". Em uma compreensão semelhante, Neves (2013, p. 97) defende que a autonomia docente "não é um valor absoluto, fechado em si mesmo, mas um valor que se define numa relação de interação social". Ele ainda argumenta que igualmente como a democracia sustenta-se em "princípios de justiça e de igualdade que incorporam a pluralidade e a participação, a autonomia da escola justifica-se no respeito à diversidade e à riqueza das culturas brasileiras, na superação das marcantes desigualdades locais e regionais e na abertura à participação." (NEVES, 2013, p. 99).

\section{Democracia e participação nas políticas educacionais: caminhos da proposta de base nacional comum curricular?}

Como dito anteriormente, a BNCC é defendida como o resultado de um trabalho coletivo. Afirma-se que "seu processo de elaboração foi conduzido pelo MEC, Consed, Undime e CNE, com a participação da sociedade civil, de professores e de gestores" e que "houve três etapas de revisão, a partir de sugestões de aprimoramento feitas por especialistas, por educadores e pela sociedade" (BRASIL, 2018, s/p). Além disso, o CNE (CNE/CP $N^{\circ}$ 2/2017), sobretudo, considerando as audiências públicas realizadas em alguns estados brasileiros, afirma que:

[...] os mais diversos segmentos da sociedade tiveram real oportunidade de participação, e efetivamente ofereceram suas contribuições, as quais se consubstanciaram em documentos essenciais para que este Projeto de Resolução, elaborado pelo Conselho Nacional de Educação, de fato refletisse as necessidades, os interesses, a diversidade e a pluralidade, presentes do panorama educacional brasileiro, e os desafios a serem enfrentados para a construção de uma Educação Básica Nacional, nas etapas da 
educação infantil e o ensino fundamental, que seja verdadeiramente democrática e de qualidade (CNE/CP No 2, 2017, p. 3).

Em vistas disso, consideramos importante discutir sobre o conceito de participação a fim de problematizarmos a questão posta neste texto. Percebemos, em nossos estudos, que o debate sobre participação se tornou, segundo Pateman (1992, p. 9), parte do vocábulo político popular, especialmente nos últimos anos da década de 1960. A autora explica que isso foi decorrente de uma "onda de reinvindicações, em especial por parte dos estudantes, pela abertura de novas áreas de participação, neste caso na esfera do Ensino Superior, e também por parte de vários grupos que queriam na prática, a implementação dos seus direitos que eram na teoria".

Santos e Avritzer (2002, p. 55) observaram que "a reinvenção da democracia participativa nos países da América do Sul, está intimamente ligada aos recentes processos de democratização pelos quais passaram esses países". No caso do Brasil, os autores afirmam que o país esteve, ainda que muito ambiguamente, por algum tempo no campo democrático, embora alternando períodos autoritários.

Todavia, nesse estudo, os autores perceberam que essa "redemocratização não passou pelo desafio de limites estruturais da democracia, como supunha a discussão sobre democracia nos anos 60". Eles analisaram que o que "a democratização fez foi, ao inserir novos autores na cena política, instaurar uma disputa pelo significado de democracia e pela constituição de uma gramática social" (SANTOS; AVRITZER, 2002, p. 54).

O que está nessa disputa segundo Alvarez, Dagnino e Escobar (2000, p. 15) "são os parâmetros da democracia, são as próprias fronteiras do que deve ser definido como arena política: seus participantes, instituições, processos, agenda e campo de ação". Por isso, dada a complexidade do fenômeno da democracia nas dimensões da prática, não é uma tarefa simples conceituá-la. Dentre os aspectos dessas tensões, está o conflito que se estabelece entre democracia representativa e democracia participativa, o qual Santos e Avritzer (2002) também discutem.

Além do citado trabalho de Santos e Avritzer (2002), outros estudos, como os de Cruz (2008), analisam essa tensão que se estabelece na dimensão democrática entre participação e representação no contexto brasileiro. Nessa análise, a autora percebeu que o abismo criado entre a participação e a representação se dá pelos "preceitos que regem a democracia representativa", os quais "conferem aos representantes a legitimidade para a tomada de decisão" e que, em geral, esvaziam "o estímulo às experiências participativas". Para a autora, a representação refere-se à "legitimidade para decidir sobre políticas públicas." (SANTOS; AVRITZER, 2002, p. 206).

Essa questão é tratada por Santos e Avritzer (2002) quando assinalam que o modelo da perspectiva da representação impõe a supervalorização dos seus próprios mecanismos em detrimento dos mecanismos societários de participação. Argumenta-se então que, quanto for menor a participação, maior será a condição para a governabilidade.

Por outro lado, Gadotti (2014) escreve que a participação social acontece através da organização de espaços e mecanismos do controle social. Ele a entende "como categoria e como conceito metodológico e político", considerando-a "fundamental para o controle, a fiscalização, o acompanhamento e a implementação das políticas públicas, bem como para o exercício do diálogo e de uma relação mais rotineira e orgânica entre os governos e a sociedade civil" (GADOTTI, 2014, p. 2).

Contudo, é importante ressaltar que a simples participação em debates, embora represente uma das possibilidades do exercício democrático, bem como um instrumento de aprendizado político, como afirma Pateman (1992), corre-se o risco de, através desse reducionismo, não se alcançar o pleno exercício de poder por parte da população. Em consequência disso, compromete-se a continuidade das ações, o que resulta no fortalecimento do sentimento de ilegitimidade política.

Gadotti (2014, p. 4, grifo nosso) discute que para que essa participação, por meio de um novo modo de governar, legitime-se, "depende de condições concretas de participação". Ou seja, o autor entende que "não basta criar mecanismos de participação popular e de controle social das políticas públicas de educação; é preciso atentar para a necessidade de criar, também, simultaneamente as condições de participação" (p. 04).

Concordamos com Pateman (1992) quando ela entende que através da participação, além do autodesenvolvimento do sujeito, é estimulada nesse sujeito uma empatia pelos problemas sociais coletivos. Mas que isso, só é possível através da 
democratização dos sistemas políticos, a "Democratização da Democracia" (SANTOS; AVRITZER, 2002). Dessa maneira, especialmente no que se refere ao campo das políticas educacionais, torna-se necessário o rompimento com a "lógica da participação restrita", requerendo "a superação dos processos de participação que não garantem o controle social dos processos educativos, o compartilhamento das decisões e do poder, configurando-se muito mais como mecanismo legitimador de decisões já tomadas centralmente." (BRASIL, 2014, p. 74).

Por outro lado, Lüchmann (2006) afirma que o reconhecimento da apatia ou baixo nível no que tange à participação dos atores está relacionado com as desigualdades sociais. Além disso, a autora apresenta a ideia já citada, defendida por Gadotti (2014) e Pateman (1992), que é referente à carência de recursos materiais, a qual impede os processos participativos, ou seja, a ausência da garantia das condições de participação.

Portanto, no entendimento de Gadotti (2014, p. 4), a dificuldade da participação da sociedade está diretamente relacionada à formação para tal: "A participação, para ser qualificada, precisa ser precedida pelo entendimento - muitas vezes técnico e científico - do que se está discutindo". No mais, essa participação "não pode ser alguma coisa episódica, paralela, mas estrutural; ela deve constituir-se numa metodologia permanente da política educacional, num modo de governar" (GADOTTI, 2014, p. 4, grifo nosso). Ademais, necessita-se, conforme o autor, da criação de planos estratégicos de participação. Planos esses que se contraponham aos "aos modelos burocratizados de planejamento, baseados numa visão instrumental e técnica do planejamento", mas que represente um "planejamento dialógico $e$ participativo" que "incentiva processos e práticas coletivas, com vistas a transformar e não a legitimar o já dito, o já feito, o já pensado". Esse fenômeno rejeitado por Gadotti (2014) orienta-se na direção dos estudos realizados por Pateman (1992) e Ball (1987).

Pateman (1992) alerta que muitas vezes o termo "participação" é utilizado em duas situações: uma para se referir a um método de tomada de decisão, outra para abranger técnicas utilizadas para persuadir os subordinados a aceitarem decisões já tomadas pela administração. É nesse ponto que os autores discutem sobre o que chamam de "pseudoparticipação".

Paterman (1992) concorda com Gadotti
(2014) quando afirma que para que a participação ocorra existe uma condição que precisa ser necessariamente satisfeita. Essa condição refere-se justamente à posse, por parte dos envolvidos, de devidas informações sobre as quais possam basear a sua decisão. Ela explica que, na prática, isso pressupõe um considerável aumento no fornecimento de informação em relação ao que em geral está acontecendo no momento: os interesses, as disputas, os objetivos etc.

No mais, Paterman (1992) analisa que, nesse modelo de participação, o que se consegue é influenciar a decisão. No final do processo, a prerrogativa da tomada de decisão final é de quem está "no comando". Assim, a autora traz um novo conceito a essa participação, chamada de participação parcial. Neste, o sujeito não tem igual poder de decisão sobre o resultado final do que se delibera, podendo apenas influenciá-lo. Portanto, esse é um processo no qual duas ou mais partes influenciam-se reciprocamente na tomada de decisões, mas o poder final de decidir pertence a uma só parte.

Ball (1987, p. 130), por sua vez, observa que, embora se celebre a autonomia dos espaços de participação, esses sujeitos aceitam o "conjunto de restrições sobre sua participação na tomada de decisões". Ou ainda, esses "direitos de participação" tornam-se simplesmente um ritual político que presta apoio a algo que na realidade é um sistema autocrático, outorgando-lhe uma falsa legitimidade.

Cruz (2008, p. 206) analisa que "historicamente, o Estado brasileiro foi fundado sob práticas centralizadoras, tornando legítimas toda e qualquer ação ou decisão dos que detêm o poder político". Assim, considerando o "histórico de fraca organização social, intermediada por períodos longos de regimes autoritários, não se pode negar que a sociedade brasileira é caracterizada pela apatia em termos de participação". A autora explica que, de um modo geral, a sociedade "não se envolve diretamente nos assuntos políticos, depositando nas mãos do governo a tarefa de decidir e agir. E o fortalecimento da democracia representativa vem corroborando este fato". Assim como Ball (1987), a pesquisadora pensa que a participação está diretamente relacionada às posturas ideológicas e políticas dos governos e a sua abertura para a mesma. Quanto mais autoritário for o sistema, menores são as chances de participação, assim como o inverso.

Obviamente, seria possível identificarmos, como afirmado por Santos e Avritzer (2002), 
experiências exitosas de participação no Brasil, em especial advindas de projetos políticos de esquerda. No caso da Educação, Dourado (2014) destaca a instituição de Conferência Nacional de Educação (CONAE).

Todavia, o caso da CONAE não se torna uma regra no que tange à participação social na construção de políticas públicas educacionais no Brasil. O país, segundo Severino (2014), é marcado pelas experiências autoritárias e discriminadoras. $\mathrm{O}$ autor observa que no campo das políticas educacionais, a exemplo de medidas como os Parâmetros Curriculares Nacionais para a Educação Básica e as Diretrizes Curriculares Nacionais para o Ensino Superior, prevalece a "lógica do pragmatismo dos organismos internacionais de financiamento do país, tudo envolvido no caldo ideológico do neoliberalismo, totalmente atrelado à concepção tecnicista e pragmática da formação humana" (SEVERINO, 2014, p. 34).

Como assinala Arelaro (2007, p. 903), percebemos, através do quantitativo mínimo de experiências bem-sucedidas quanto aos mecanismos de participação efetiva, que estas iniciativas constituem "referências importantes para se entender que, na modernidade, a participação popular e a gestão democrática representam pontos frágeis e polêmicos também nos governos democráticos".

Arelaro (2007, p. 902), concordando com os autores já apresentados nesse texto, analisa que a possibilidade de uma definição mais adequada das políticas educacionais e, em especial, uma maior coerência na sua "implementação", depende das "condições de participação popular, em que os grupos sociais tiveram a possibilidade de conhecer de perto os dirigentes públicos e com eles discutir ideias, propostas e suas necessidades locais, regionais e nacionais".

Entretanto, a autora salienta que "este é um processo que implica, por definição, uma tramitação democrática, em que o ritual de reuniões sistemáticas preveja que todos os presentes possam se manifestar". Em virtude disso, esses encontros precisam ser realizados "com intervalos compativeis, que permitam aos "representantes" dos diversos grupos - delegados eleitos ou escolhidos consultar seus "representados", trazendo sempre reflexões e sugestões dos mais amplos segmentos" (ARELALO, 2007, p. 902). O obstáculo para essa realização, segundo Arelaro (2007, p. 903, grifo nosso), é a "pressa nas decisões de políticas públicas", o que "compromete esse processo democrático - sempre mais lento - de consulta aos envolvidos".

É nesse contexto que surgiram as proposituras de Parâmetros Curriculares Nacionais para a Educação. Teixeira (2006) afirma que a publicação dos PCN's, no tocante à participação social na tessitura da política curricular, deveria ter contado com amplo processo de discussão na sua elaboração, no entanto, foi elaborada antes que fosse apresentada à sociedade.

Apesar das inúmeras críticas que essas experiências educativas suscitaram, elas serviram de base ao trabalho do Governo Federal, através do MEC, na proposta a BNCC para a Educação brasileira. Dada a "importância do currículo no exercício do ato pedagógico" (CURY, 2014, p. 50), inúmeros posicionamentos suscitaram sobre o documento referente às mais diversas dimensões da política. E, assim como no caso dos PCN's, destacaram-se algumas limitações do processo de tessitura curricular com relação aos espaços de participação social.

Endossando a necessidade de um espaço efetivamente participativo, a CNTE (2015) assinalou que o documento só será materializado na escola se partir de uma construção participativa dos profissionais da Educação. Caso isso não aconteça, "o que se tem é apenas uma retórica, camuflada de interesses ideológicos que não se explicitam claramente" (SEVERINO, 2014, p. 32).

Nesse sentido, entendemos, assim como Santos e Avritzer (2002), que os perigos da "burocratização da participação", da "reintrodução de clientelismo", da "exclusão de interesses subordinados através do silenciamento" ou "manipulação das instituições participativas" só podem ser evitados "por intermédio da aprendizagem e da reflexão constantes para extrair incentivos para novos aprofundamentos democráticos" (p. 75). Portanto, as tarefas de democratização só se sustentam quando elas próprias são definidas por processos democráticos cada vez mais existentes.

Dessa maneira, uma concepção realmente democrática do e no processo educativo, e especificamente no caso da BNCC, exigiria a ampliação e $\mathrm{o}$ fortalecimento das formas de participação. Para que o projeto democrático tornese factível e real, ele deverá ser construído a partir de um projeto coletivo, no qual a presença efetiva de outros atores é uma realidade. Ou seja, a democratização pressupõe aprendizado e vivência no exercício de tomadas de decisões. 


\section{A BNCC e a micropolítica da escola: a escuta e a voz dos atores da prática}

De acordo com Ball (1987), a política é um processo complexo de construção e reconstrução. Além disso, o autor ressalta a importância da experiência prática e o conhecimento que os atores da prática possuem na compreensão do ciclo da política.

Os dados a seguir apresentados são resultado de um estudo de caso realizado no Município de João Pessoa - PB, através de uma pesquisa de dissertação de Mestrado. A Rede Municipal da cidade é composta por 92 (noventa e duas) escolas, estando estas distribuídas em 9 (nove) polos. Para a escolha da amostragem de nossa pesquisa, interessamo-nos, inicialmente, em investigar um número de nove escolas, devido a essa distribuição. Essa decisão, a princípio, apontava para a possibilidade de aleatoriamente demonstrarmos uma representação da totalidade das instituições.

No entanto, a escolha da nossa amostra de pesquisa sofreu a influência da nossa interlocução com a Secretaria de Educação do Município de João Pessoa e mais especificamente com o grupo responsável pela mobilização e participação das escolas da Rede Municipal no processo de elaboração do documento da BNCC. Esse diálogo reorientou o percurso metodológico desse estudo.

Após apresentar para o citado grupo os objetivos da nossa pesquisa, questionamos sobre a composição e organização da equipe. Como resposta, o conjunto afirmou para nós que estava divido em três comissões: a representativa, a de articulação pedagógica e a de sistematização. A primeira comissão consistia na coordenação institucional e estava representada pela Secretaria municipal de Educação - SEDEC, Conselho Municipal de Educação - CME, Fórum Municipal de Educação - FME, União Nacional de Conselhos Municipais em Educação - UNCME, União Nacional dos Dirigentes Municipais de Educação UNDIME, Universidade Federal da Paraíba UFPB, Fórum EJA, ONG's, representantes de Escola Pública Municipal e representantes de CREIS. A comissão denominada de articulação pedagógica era composta por um grupo de especialistas (Pedagogos) escolhidos pelo SEDEC. A finalidade de formar o grupo foi mobilizar e organizar a discussão sobre a BNCC com os respectivos polos.

A equipe da SEDEC também nos informou que foram enviadas correspondências para as escolas e Centros de Referência de Educação Infantil (CREI's), afirmando a importância de discutir sobre a BNCC e convidando-os para apoiar nos processos de divulgação e contribuições. Após o convite, foram realizadas duas reuniões: uma com os gestores, a fim de discutir sobre a proposta e outro encontro separadamente com os coordenadores dos polos. No entanto, segundo a equipe, alguns especialistas escolhidos de três polos não participaram das reuniões e não deram o retorno solicitado.

Assim sendo, a partir das informações obtidas, selecionamos, na pesquisa de Mestrado, como amostragem as doze escolas, distribuídas entre os nove polos da Rede Municipal de Ensino de João Pessoa. Nelas, foram selecionados pela SEDEC os especialistas escolhidos como membros da comissão de articulação pedagógica. Essa escolha se dá pela nossa preocupação principal em analisar os processos de participação e contribuições das escolas. No entanto, sentimos de igual forma a necessidade de ouvir os professores que fazem o currículo praticado nas escolas, estes que compõem o cotidiano das salas de aula e cujo trabalho tem estreita relação com a BNCC.

Ressaltamos, no entanto, que o presente texto é um recorte da citada pesquisa. Embora tenhamos ouvido outros atores da política da BNCC para nossa análise, preocupamo-nos, aqui, em destacar os achados que têm relação direta com à Base: os professores e profissionais da educação que estão na escola. Por isso, entendemos a necessidade de realizar uma escuta atenta do que esses profissionais tinham a dizer. Porque como Cury (2014) alertou, não é possível legitimar uma proposta curricular sem considerar a subjetividade desses sujeitos.

Preocupamo-nos em analisar os processos de participação e contribuições das escolas e especialmente dos docentes. Pois, para Ball (1987), os dados na pesquisa sobre a escola são as ideias, experiências, significados e interpretações dos atores sociais envolvidos na dinâmica escolar. E neste caso, segundo o referido autor, esses sujeitos são quase que exclusivamente os professores. Mas isso significa desconsiderar a maioria dos que participam dos dramas sociais da educação. Ele admite que os alunos e outros que trabalham na escola desempenham um papel na micropolítica da vida escolar.

O mesmo pesquisador propõe, então, que seja desenvolvida uma análise a partir da interação 
entre esses dados, através dos relatos ditos pelos atores. Esses dados são o ponto de partida e o ponto de referência contínua da análise. Em concordância com esse pensamento, Gatti e André (2011) afirmam que uma das importantes contribuições das pesquisas qualitativas é considerar o ponto de vista dos sujeitos, ou seja, ouvir os atores envolvidos no processo educacional. Assim, nossa tentativa de identificar os efeitos no campo da prática será realizada pela coleta de informações via entrevistas semiestruturadas. No roteiro planejado para os professores/as, interessamo-nos em identificar o que eles pensam sobre a política curricular e como qualificam o processo de elaboração da BNCC: de quais maneiras foram envolvidos/as? Como avaliam o movimento em prol da composição da base? Como as discussões sobre a política chegaram à escola? Nosso interesse é, portanto, mapear, nas vozes desses sujeitos, como discernem a política da $\mathrm{BNCC}$ e de que forma se percebem presentes nessa dinâmica.

Nesses dois casos, buscamos realizar uma análise baseada diretamente na experiência desses atores no processo de elaboração da BNCC, revelando "suas ideias, preocupações e interesses reais e práticos" (BALL, 1987, p. 33). Destacamos algumas respostas que, para nós, expressaram essas questões, as quais serão apresentadas a seguir.

Através dessas conversas, foi possível descortinar alguns sentidos sobre a política da BNCC para essa análise. Além de "pressa e o autoritarismo da proposta", outros aspectos foram mencionados nas vozes dos professores, os quais serão apresentados mais adiante. Nesses debates (transcritos) nosso principal objetivo foi investigar como esses docentes sentiram-se partícipes do processo de tessitura da BNCC.

Embora tivéssemos levado um roteiro para aquela discussão, os docentes adiantaram-se sobre algumas questões, o que exigiu de nós certa flexibilidade durante as conversas. No caso da escola A, o primeiro tema tratado pelas docentes foi referente à apresentação da proposta à escola. Argumentaram que o grande problema da política estava na forma e nos meios para discussão. Uma das professoras, a qual será chamada de P1, afirmou só ter tido uma discussão mais reflexiva através da Universidade Federal da Paraíba, em um Colóquio sobre políticas curriculares. Ela afirmou que o evento foi divulgado pela supervisora e que nem todos puderam ir. No entanto, P1 afirmou que, enquanto professora da Educação Básica, não teve espaço para ser ouvida ou participar de maneira mais efetiva de outras discussões como aquela. A Secretaria não havia possibilitado isso. Outra professora, P3, complementou a afirmação com a seguinte frase: "No colóquio, foi a primeira vez que vi o "outro lado" da discussão. Porque conhecíamos o lado oficial. Mas, uma pessoa que estava na sala de aula só teria acesso a uma face da moeda e olhe lá".

A partir do que as professoras P1 e P3 afirmaram, pensamos que o evento caracterizou-se como uma das arenas de influência citadas por Bowe, Ball e Gold (1992). Na medida em que ele mostrou o "outro lado da moeda", foi capaz de produzir sentidos sobre a política de BNCC.

Ainda sobre o assunto em torno dos debates sobre a proposta, questionamos as professoras da Escola A sobre o Seminário Estadual da Paraíba, se participaram ou foram comunicadas do evento, e também solicitamos que narrassem suas experiências no dia nomeado "Dia D da BNCC". A professora P2 afirmou, em relação ao Seminário Estadual, não terem ido e que não sabiam da realização do evento: "Só ficamos sabendo quando as inscrições já haviam acabado. Não foi divulgado pra nós", afirmou.

Sobre a experiência da escola no dia D da $\mathrm{BNCC}$, as professoras $\mathrm{P} 2$ e $\mathrm{P} 4$ assinalaram que a discussão realizada entre elas ocorreu em um horário de planejamento. Afirmaram que a escola não parou suas atividades para aquele debate e que a discussão foi, de certa maneira, improvisada. P4 continuou o assunto e afirmou que "em outras escolas, através de um grupo do WhatsApp, [aplicativo de comunicação instantânea para celulares] surgiu o assunto sobre o dia D da BNCC. Muitos professores não sabiam nem do que se tratava. [...] algumas escolas passaram do dia $D e$ não foram convocados nem avisados". P4 também questionou: "então, o que eu interpreto? Que o documento ficou decidido entre gestão $e$ supervisão".

A partir dessas citações, e com base nos estudos de Bowe, Ball e Gold (1992, p. 178), colocamos sob suspeita a fonte ou o momento das tomadas de decisões que envolvem a escola. Assim como afirmou os autores e questionou P4, "as decisões parecem simplesmente emergirem", ao invés de serem tensionadas e discutidas. $\mathrm{O}$ centro dessa questão reside na "falta de clareza e de informações sobre as decisões e planejamento". Questionamos então: como defender que a política foi participativa? Essas vozes foram consideradas em algum momento da construção? 
Outros elementos trazidos para nossa conversa sobre a BNCC pelos docentes foram concernentes à participação e a unificação do ensino. Quando questionado sobre o sentido da BNCC para seu trabalho pedagógico, o professor P8 afirmou que o documento veio como uma imposição, "sem discussão [...] e chegou de última hora". Além disso, disse que, a seu ver, "eles querem unificar o ensino e tirar a identidade regional de cada sistema". A professora P6 complementa sua fala e afirma que "para a BNCC todo mundo é igual [...] aí, dizem que tem uma parte diversificada [...] mas, na verdade, acentuam e desprezam a realidade local". Sobre a questão, P8 justificou suas afirmações trazendo uma exemplificação real do seu cotidiano. Ele afirmou:

Por exemplo, os livros de Ensino de Geografia são feitos por autores do Sudeste e por isso trazem geralmente imagens do Nordeste que se reduzem à seca, miséria e pobreza. Mas a gente sabe da nossa diversidade. Então, percebo que eles não partem de uma perspectiva dialógica e nem crítica, é algo isolado. Vejo que são muitos conteúdos, mas vazios, que buscam engessar a estrutura [...] é uma questão de poder e esse é o caso da BNCC. (Dados da pesquisa, transcrição)

Aqui, percebemos outra questão trazida por Bowe, Ball e Gold (1992). Evidenciamos que P8 não confrontou o texto político como um leitor ingênuo. Ele trouxe "suas experiências, valores e propósitos" e expressou seus interesses no significado da política. Em outro trabalho, Ball (1987) analisa que a intervenção quando chega à micropolítica, não se defronta com profissionais maleáveis e passivos, eles, por sua vez, interpretam a política à luz de suas necessidades e conveniências.

Por outro lado, o referido autor analisa que esses interesses carregam fortes laços ideológicos que coexistem conflitantemente na micropolítica. Percebemos essa questão quando os professores pontuam algumas queixas em suas avaliações sobre a proposta da BNCC. P8 afirmou considerar que o outro problema em relação à política curricular é que "atualmente não podermos falar de política" e, no caso de seu componente curricular (Geografia), "é inevitável falar disso". A esse respeito, P7 afirmou que "a ideia da BNCC é assim: Pedro Álvares Cabral descobriu o Brasil e os índios aceitaram e pronto".

Para o professor $\mathrm{P} 7$, a BNCC tira a criticidade. Ele finaliza afirmando que "a ideia do
Ensino de História é gerar esse momento de crítica, mas [...]". P8 ainda completou e trouxe outro exemplo sobre esse aspecto. Ele nos disse que "o documento fala em Geografia do processo de formação do povo brasileiro [...] e, quando trata da miscigenação, o documento não fala que isso aconteceu de forma violenta [...] através do estupro [...] não problematiza". Portanto, o P8 vê "que o arranjo é esse: uma BNCC, uma Escola sem Partido, 20 anos de congelamento de investimento [...] pra quê? Pra continuar a se perpetuar o poder".

Entendemos que essas afirmações mais uma vez confirmam que os professores não estão em sua totalidade, despolitizados e alheios às questões mais amplas da sociedade e da Educação, como mencionado anteriormente pela equipe de especialistas do MEC. Além disso, ratificou-se, na conversa com a Escola B, a necessidade de reavaliarmos a questão da participação e os canais disponibilizados para tal na tessitura do documento. P6 finalizou nossa conversa afirmando: "democrático pra mim não é colocar um texto pra todo mundo olhar. Os professores contribuíram como? [...] mas não tivemos nem sequer tempo de ler o documento na íntegra [...] tivemos dois dias pra ler tudo, debater e contribuir [...] não dá".

Entendemos, a partir dessas narrativas, que, como Ball (1987, p. 144) afirmou, as decisões fundamentais concernentes à BNCC foram tomadas fora da escola. E, além disso, a linguagem dos discursos exprimem "a oposição e antagonismo consciente de interesses entre "os de baixo" e os elaboradores da política. Percebemos, dessa forma, que a cultura política da BNCC "se baseia em uma concepção limitada de democracia e participação" e, além disso, "mediante a aplicação de técnicas da administração, os problemas ou questões que podem ter aspectos valorativos ou ideológicos podem ser traduzidos em assuntos técnicos e deste modo, despolitizados" (BALL, 1987, p. 142).

\section{Considerações finais}

Após a apresentação feita acima, queremos considerar alguns apontamentos. Um deles é que, para nós, o caráter participativo da política da BNCC representou "uma espécie de compromisso em que as decisões são tomadas de modo formativo" e, por outro lado, "surge em termos de fazer as coisas" (BOWE; BALL; GOLD, 1992, p. 175). A plataforma da BNCC, nesse sentido, é determinante, como afirmamos, pois, fora desse 
sistema estruturado e tendencioso, não haveria participação.

Além do mais, outras duas questões poderiam ser postas. A primeira é que visivelmente se dicotomiza o grupo que planeja do grupo que legitima e executa o projeto. Como os autores citados afirmam, é o modelo e o tipo de política desempenhada que reforça essa separação. Outro aspecto que merece atenção é referente às questões de tempo. Identificamos, aqui, que a consulta pública tornou-se a opção mais apropriada, porque se a participação não se desse de modo burocratizado, o controle não se estabeleceria e, além disso, demandaria mais tempo. Então, dada a pressão pelo tempo e pelo ritmo que deveria ser seguido, optou-se por um "estilo gerencial de tomada de decisões" (BOWE, BALL \& GOLD, 1992, p. 175). A consulta pública representa, pois, "um aditivo em vez de decisões fundamentais" (BOWE; BALL; GOLD, 1992, p. 176).

Então, concluímos, com base nos autores mencionados, que "o estatuto e efeitos da consulta permanecem obscuros". Nessa ideia, "os fins instrumentais, sociais e micro políticos de consulta estão confusos e encobertos". Salientamos, igualmente, que "não há nada na forma [...] que dê valor ou credibilidade à participação [...], muito pelo contrário." (BOWE BALL; GOLD, 1992, p. 178). Em vista disso, analisaremos a seguir como esses aspectos foram interpretados pelos atores da micropolítica, a saber, da escola.

Entendemos, também, assim como assinala Santos e Avritzer (2002, p. 75), que os perigos da "burocratização da participação", da "reintrodução de clientelismo", da "exclusão de interesses subordinados através do silenciamento" ou "manipulação das instituições participativas" só podem ser evitados "por intermédio da aprendizagem e da reflexão constantes para extrair incentivos para novos aprofundamentos democráticos". E que a "democracia é um princípio sem fim, e as tarefas de democratização só se sustentam quando elas próprias são definidas por processos democráticos cada vez mais existentes" (SANTOS; AVRITZER, 2002, p. 75).

Dessa maneira, uma concepção realmente democrática do e no processo educativo exige a ampliação e o fortalecimento das formas de participação. Para que o projeto democrático tornese factível e real, ele deverá ser construído a partir de um projeto coletivo, no qual a presença efetiva de outros atores seja uma realidade. Isto é, a democratização pressupõe aprendizado e vivência no exercício de tomadas de decisões.

Embora devamos considerar que a política de BNCC encontra-se em desenvolvimento, não queremos indicar que essas análises apontaram para elementos iniciais ou transitórios do projeto. Estes, por sua vez, revelam características e aspectos inerentes à política. Esperamos que todos os profissionais da educação que contribuíram com essa análise possam não somente sentir-se contemplados nessas palavras, mas que, sobretudo, elas reverberem em análises mais profundas tanto de suas práticas cotidianas, quanto do entorno mais amplo que envolve e disputa pela escola.

\section{Referências}

ALVAREZ, S. E.; DAGNINO, E.; ESCOBAR, A. (orgs.). Cultura e política nos movimentos sociais latinoamericanos: novas leituras. Inserir edição. Belo Horizonte: UFMG, 2000.

APPLE, M. W. Política cultural e educação. São Paulo: Cortez, 2000.

ARELARO, L. R. G. Formulação e implementação das políticas públicas em Educação e as parcerias público-privadas: impasse democrático ou mistificação política? Revista Educ. Soc. Campinas, v. 28, n. 100. Especial. Out. 2007. p. 899-919.

BALL, S. Diretrizes políticas globais e relações políticas locais em educação. Revista Currículo sem Fronteiras. v. 1, n. 2. Jul./Dez. 2001. p. 99-116.

- La micropolítica de la escuela: hacia uma teoria de la organización escolar. S.A. Barcelona: Centro de Publicaciones del M.E.C. y Ediciones Paidós Ibérica, 1987.

Sociologia das políticas educacionais e pesquisa crítico-social: uma revisão pessoal das políticas educacionais e da pesquisa em política educacional. Currículo sem Fronteiras. v. 6, n. 2. Jul./Dez. 2005. p. 10-32.

BOURDIEU, P. Os usos sociais da ciência: por uma sociologia clínica do campo científico. Tradução de Denice Barbaro Catani. São Paulo: UNESP, 2004.

BOWE, R.; BALL, S.; GOLD, A. Reforming 
education \& changing schools: case studies in policy sociology. London: Routledge, 1992.

BRASIL. $O$ PNE na articulação do Sistema Nacional de Educação: Participação Popular, Cooperação Federativa e Regime de Colaboração. Conferência Nacional de Educação. Documento de referência. 2014.

BRASIL. Base nacional comum curricular: proposta preliminar. $2^{\mathrm{a}}$ versão revista. MEC: 2016.

BRASIL. Base nacional comum curricular: proposta preliminar. Material de Apoio. MEC: 2018.

CURY, C. R. J. A Lei de Diretrizes e Bases da Educação Nacional e a base nacional comum. In: BRZEZINSKI, I.. LDB 1996 Contemporânea: contradições, tensões e compromissos. $1^{\text {a }}$ edição. São Paulo: Editora Cortez, 2014.

CRUZ, G. R. Participação versus representação: o dilema da legitimidade política. Revista ALCEU. v. 8, n. 16. Jan./Jun. 2008, p. 205-215.

CNTE, Confederação Nacional dos Trabalhadores em Educação. Considerações da CNTE sobre o Projeto de Base Nacional Comum Curricular, elaborado preliminarmente por CUNHA, L. A. Os parâmetros curriculares para o ensino fundamental: convívio e ética. Faculdade de Educação da UFRJ. Cad. Pesq. Temas em Debates. São Paulo, n. 99. Nov. 1996. p. 60-72.

GADOTTI, M. Gestão democrática com participação popular no planejamento e na organização da educação nacional. Coletânea de textos da CONAE. Tema Central de Colóquios. 2014.

GATTI, B. A.; ANDRÉ, M. A relevância dos métodos de pesquisa qualitativa em educação no Brasil. In: WELLER, W.; PFAFF, N. (Orgs.). Metodologias da pesquisa qualitativa em Educação: teoria e prática. 2. ed. Petrópolis: Vozes, 2011. p. 29-38.

LÜCHMANN, L. H. H. Os sentidos e desafios da participação. Revista Ciências Sociais - UNISINOS. v. 42, n. 1. Jan./Abr. 2006. p. 19-26.

MOREIRA, A. F. B. Em busca da autonomia docente nas práticas curriculares no Brasil. In: OLIVEIRA, M. R. N. S. PACHECO, J. A. Currículo, didática e formação de professores. Campinas - SP: Papirus, 2013. p. 27 a 47.
NEVES, C. M. Autonomia da escola pública: um enfoque operacional. In VEIGA, I. P. A. (Org.). Projeto político-pedagógico da escola: uma construção possível. São Paulo: Papirus, 2013.

OLIVEIRA, Inês B. Currículos praticados: entre a regulação e a emancipação. Rio de Janeiro: DP\&amp; A, 2003.

PATEMAN, C. Participação e teoria democrática. Rio de Janeiro: Paz e Terra, 1992.

PEREIRA, M. Z. C. A Centralidade da pluralidade Cultural nos Debates Contemporâneos no Campo do Currículo. Revista Currículo sem Fronteiras. v. 9. 2009. p. 169-184.

Currículo e autopoiése. $1^{\text {a }}$ edição. João Pessoa: Editora Universitária da UFPB, 2010. PEREIRA, M. Z. C. SANTOS, E. S. Políticas e práticas curriculares em tempo de Globalização. Revista Temas em Educação. Versão Impressa. v. 15. 2006. p. 13-22.

SANTOS, B. S. AVRITZER, L. Para ampliar o cânone democrático. In: SANTOS, B. S. (org.). Democratizar a democracia: os caminhos da democracia participativa. Rio de Janeiro: Civilização Brasileira, 2002.

SANTOS, B. de S.. Pela mão de Alice: o social e o político na pós-modernidade. São Paulo: Cortez Editora, 1995.

SANTOS, B. de S.. Renovar a teoria crítica e reinventar a emancipação social. São Paulo: Boitempo Editorial, 2007

SEVERINO, A. J. Os embates da cidadania: ensaio de uma abordagem filosófica da LDB/1996. In: BRZEZINSKI, I. LDB 1996 Contemporânea: contradições, tensões e compromissos. São Paulo: Editora Cortez, 2014.

SILVA, T. T. Documentos de identidade: uma introdução às teorias do currículo. 3. ed. Belo Horizonte: Autêntica, 2013.

SÜSSEKIND, M. L. As (im)possibilidades de uma Base Comum Nacional. Revista e-Curriculum. São Paulo. v. 12, n. 3. Out./Dez. 2014. p. 1464-1479.

TEIXEIRA, B. B. PCN do ensino fundamental: teoria e prática do currículo na rede estadual de ensino em Juiz de Fora. Relatório de Pesquisa. Universidade Federal de Juiz de Fora, 2006. 


\section{Sobre as autoras}

Nathália Fernandes Egito Rocha: Pedagoga pela Universidade Federal da Paraíba (UFPB); Mestre em Educação na linha de Políticas Educacionais pelo Programa de Pós-Graduação em Educação (PPGE) da UFPB. Atualmente é doutoranda pelo PPGE/ UFPB na linha de Políticas Educacionais, Professora Substituta do Departamento de Habilitações Pedagógicas da UFPB e membro do Grupo de Estudos e Pesquisas de Políticas Curriculares.

Maria Zuleide da Costa Pereira: Graduação em Licenciatura Em Pedagogia pela Universidade Federal da Paraíba (1990), mestrado em Educação pela UFPB (1995) e doutorado em Educação pela Universidade Metodista de Piracicaba (2001). Pós- doutorado em Educação na UERJ (2008) Professora Titular da UFPB, atuando na graduação e pós-graduação. É líder do Grupo de Estudos e Pesquisas em Políticas Curriculares.

Recebido em novembro de 2017.

Aprovado em março de 2018. 